\title{
MOTIONS STUDY OF A SINGLE CYLINDER HIGH SPEED SPARK IGNITION LINIER ENGINE WITH SPRING SYSTEM AS RETURN CYCLE
}

\author{
A.Z.M. Fathallah, Semin, I.M. Ariana and I. Gerianto \\ Department of Marine Engineering, Faculty of Marine Technology \\ Institut Teknologi Sepuluh Nopember (ITS), Surabaya 60111, Indonesia
}

Received 2013-12-22; Revised 2013-12-27; Accepted 2014-01-17

\begin{abstract}
A single cylinder two stroke spark ignition conventional engine have been modified to linier engine with spring mechanism. Before develop the design of linear engine is necessary to analysis of motion. Although principle of combustion process in combustion chamber is the same in fact the oscillation movement is different. Simulation technique has been adopted to study both linear and conventional engine. 3D engines model have been simulate of the motion. Due to simulate both engines, three different tools have been used. Solid works has been used to design, assembly and motion analysis of engine models. However, pressure dynamics have been simulating by GT-Power. Spread sheet has been used to optimize geometry of spring. Spring force and friction force are including components of dynamic and gas dynamic models. Three results have been conducted such as comparison in basic motion (displacement, velocity and acceleration) between conventional and linear engine, effect spring design on motion of piston movement and effect friction of piston ring and journal bearing on the motion characteristics of linear engine. The simulation shows clear different motion characteristics between conventional and linear engine. The effect of spring design on motion characteristics is very strong. The friction between ring piston with cylinder liner and journal bearing with rod influenced of piston movement. However, it need modified the design of spring mechanism.
\end{abstract}

Keywords: Linear Engine, Motion Analysis, Spring System

\section{INTRODUCTION}

A spring system as a return cycle has been developed for a linear engine since it is a simple technique to be applied. Although the system is simple, some aspects related to the system need to be analysed. Currently, the motion of a linear engine with single cylinder spark ignition and a spring mechanism have been examined. The linear engine has been modified from a conventional engine. For that reason, the motion analyses are compared between linear and conventional engines. The effects of the spring design on the motion of a linear engine are also included in this study.
The optimisation of the spring design has a very strong effect on the motion of the linear engine. The geometry of the spring could affect the combustion continuity of the engine. Deflection of the spring is influenced by the thrust force of the combustion of an engine. According to Hooke's law, if the force is strong then the spring will be further deflected. A small deflection will occur if the force is weak. Hence it is very important to study the effect of the spring design on the motion of the linear engine.

Although it is believed that a linear engine has lower friction compared to a conventional engine, it is, however, difficult to ignore it until zero point. The effect Corresponding Author: A.Z.M. Fathallah, Department of Marine Engineering, Faculty of Marine Technology,

Institut Teknologi Sepuluh Nopember (ITS), Surabaya 60111, Indonesia

Tel: +62-31-5994251, Fax: +62-31-5994754 
of the spring on the piston motion has also been studied in this research. According to the design of a linear engine with a spring mechanism, the friction sources are caused by piston rings and journal bearings. The friction between the piston rings and cylinder liner is very important and cannot be ignored. The friction in bearings also has a contribution in this linear engine.

There are three main aims of the research. First, is to compare the motion between conventional and linear engines in basic motions such as displacement, velocity and acceleration. Secondly, is to study the effect of a spring design on engine motion. The final aim is to study the effect of friction on engine motion. The second and the third aims are very important, because they could influence the design of the linear engine.

\subsection{Numerical Simulation of a Linear Engine}

The spring system is rarely used to generate a linear engine system. However, in this case the compression spring has been used to absorb expansions cycle energy and a part of energy to return the compressions process. Figure 1 shows the spring system configuration used to create a single cylinder linear engine.

The numerical model is developed for a spark ignited linear engine, but can be easily adapted for the case of a compression ignition linear engine. The numerical analysis also allows a parametric study of the operation of this type of engine. The engine modelling has been validated using results from the existing works on linear engines. The numerical model represents an idealised case based on the assumptions made, while allowing a parametric study to be performed.

\subsection{The Dynamic Model}

The modelling starts with a dynamic analysis of the linear engine. They consider the case of a linear engine with spring system that oscillates back and forth in a left-to-right motion with a fixed inlet scavenging port. The expansion is conducted by combustion pressure, while the compression force is the reacting spring force. A system of coordinates was chosen with their origin at the outermost point of the left cylinder. Considering a mechanical system represented by the piston assembly in motion, this system obeys Newton's second law. This formula was also adopted by some researchers (Ahmad et al., 2006; Nik et al., 2006; Zulkifli et al., 2008; Mikalsen and Roskilly, 2008a; Christopher et al., 1999):

$$
\mathrm{m} \frac{\mathrm{d}^{2} \mathrm{x}}{\mathrm{dt}^{2}}=\sum_{\mathrm{i}} \mathrm{F}_{\mathrm{ix}}
$$

where, $\mathrm{x}$ represents the displacement of the piston assembly and $\frac{\mathrm{d}^{2} \mathrm{x}}{\mathrm{dt}^{2}}$ is the acceleration of the piston. The right hand side of Equation (1) represents the summation of the forces that act in the plane of motion.

The only forces considered to act on the moving assembly are the resultant pressure forces given by the difference between the pressures in the two cylinders, a frictional force, the inertial force and the load.

Equation (2 and 3) can be written as:

$\mathrm{m} \frac{\mathrm{d}^{2} \mathrm{x}}{\mathrm{dt}^{2}}=\mathrm{F}_{\mathrm{C}}-\mathrm{F}_{\mathrm{f}}-\mathrm{F}_{\mathrm{S}}-\mathrm{F}_{\mathrm{L}}$

$\mathrm{F}_{\mathrm{C}}=\left(\mathrm{p}_{1}-\mathrm{p}_{2}\right) \frac{\pi \mathrm{D}^{2}}{4}$

Where:

$\mathrm{F}_{\mathrm{C}}=$ The resultant of the combustion pressure forces

$\mathrm{F}_{\mathrm{f}}=$ The friction force

$\mathrm{F}_{\mathrm{s}}=$ The spring force

$F_{1}=$ The load applied to the shaft

$\mathrm{D}=$ The piston diameter, $\mathrm{p}_{1}$ and $\mathrm{p}_{2}$ are the corresponding in-cylinder pressures

In order to determine the solution of this differential equation, it is necessary to integrate it twice with respect to time. The analytic integration is somewhat complicated to evaluate due to the complex variation in the three forces with respect to space and time. However, the thrust force of the combustion process is expressed by a pressure diagram which results from a 1-D GT-power simulation analysis.

\subsection{The Friction Force}

The friction forces in the engine are a consequence of hydrodynamic stresses in oil films and metal to metal contact. Since friction losses are a significant fraction of the power produced in an internal combustion engine, the minimisation of the friction has been a major consideration in engine design and operation. The frictional processes in internal combustion engines can be categorised into three main components, the mechanical friction, the pump work and the accessory work (Ferguson and Kirkpatrick, 2000; Bakar and Ismail, 2008a; 2008b; Ismail and Bakar, 2008). The mechanical friction includes the friction of internal moving parts such as the crank shaft, piston, rings and valve train. The pumping work is the net work that is done during the intake and exhaust strokes. The accessory work is the work required for the operation of accessories such as the oil pump, fuel pump, alternator and fan. In this case, a simple two-stroke engine does not have a pump or accessory work. For that reason, the effect of both frictions can be ignored (Fathallah and Bakar, 2009). 


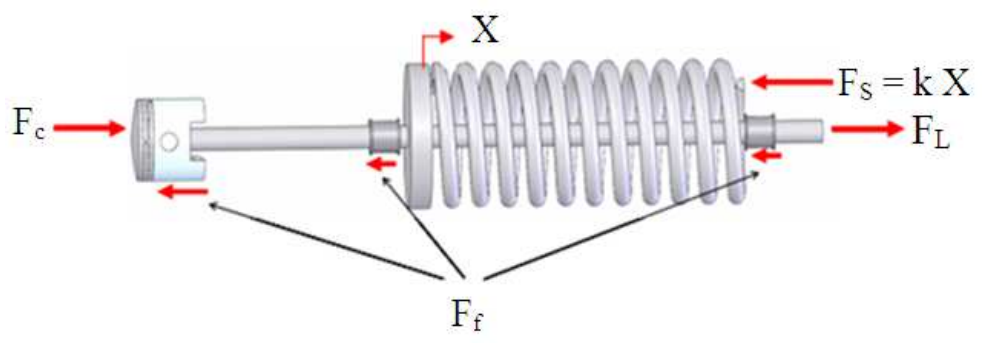

Fig. 1. Spring system design for a linear engine

The dependence of the mechanical friction mean effective pressure on the friction force, $F_{f}$ and other engine parameters depends on the friction regime and the lubrication surface geometry, such as sliding or rotating surfaces. The friction force, $F_{f}$, is the product of the friction coefficient $f$ and the normal force $F_{n}$ and the friction power $\mathrm{P}_{\mathrm{f}}$ is the product of friction force $\mathrm{F}_{\mathrm{f}}$ and $\mathrm{a}$ characteristic velocity U Equation (4 and 5):

$$
\begin{aligned}
& F_{f}=f_{n} \\
& P_{f}=F_{f} U
\end{aligned}
$$

Therefore, the mechanical friction mean effective pressure scale is Equation (6):

$$
\text { mfmep } \approx \frac{\mathrm{P}_{\mathrm{f}}}{\mathrm{NV}_{\mathrm{d}}} \approx \frac{\mathrm{F}_{\mathrm{f}} \mathrm{U}}{\mathrm{NV}_{\mathrm{d}}} \approx \frac{\mathrm{F}_{\mathrm{f}} \mathrm{U}}{\mathrm{n}_{\mathrm{c}} \mathrm{Nb}^{2} \mathrm{~S}}
$$

Where:

$\mathrm{N}=$ The engine speed

$\mathrm{V}_{\mathrm{d}}=$ The displacement volume

$\mathrm{b}=$ The cylinder bore

$\mathrm{S}=$ The piston stroke

$\mathrm{n}_{\mathrm{c}}=$ The number of cylinders

The preceding component analysis can be combined to form an overall engine fmep model. It should be noted that the component equations are likely to depend on the type of engine for which the friction regime is available. Usually fmep for a simple two-stroke conventional engine, such as the friction from a crankshaft mechanism and piston components, includes the main bearings, seals, connecting rod bearings, skirts, rings and gas pressure. However, for two-stroke linear engines, it is only the left piston rings, gas pressure and journal bearing. The detail of the components for both conventional and linear engines models have been explained by Fathallah and Bakar (2009). Their engine models have also been adopted in this research. However, the seal formula has been ignored since the design of the linear engine does not use oil seals.

\section{MATERIALS AND METHODS}

The model has been developed from a conventional engine. One of the objectives of the research is to investigate the difference between linear engines and rotating engines. The original engine needs to be redesigned. Figure 2 shows the result of the redesign of the original machine in 3-D. All components are drawn one by one and then assembled into one unit using Solid Works. Figure 3 shows the result of the modification of the linear engine which will be used to analyse the dynamics of the piston.

Two models are used for the dynamic analyses. Both models differ in the return cycle only and the combustion systems and accessories used are the same. Since all systems are in the same condition, except for the return cycle system, then the validity of the comparison of both engines can be assumed.

Figure 4 presents a flow diagram of the dynamic analysis techniques which are used in this study. GTPower, a spreadsheet, Solid Works and Cosmos are used to support the dynamic model analysis. GT-Power is used to gradually supply the pressure that is generated from the combustion process to provide input on the system's dynamic force of the spring. The spreadsheet is used to design the spring in accordance with the engine. The spring of the model must be exchanged with a flexible spring that is available from the Cosmos software database.

To simulate the friction of the piston with the cylinder liner, or between the journal-bearings with a rod, contacting surfaces are needed. Then it should define based of material, friction, or elastic properties. For the study of the dynamic friction of a piston, this simulation has been chosen to specify the material, namely friction between aluminium and steel which is greasy. The oscillation motion is simulated by choosing a linear motor whose oscillating pattern has been selected according to displacement and frequency and can be adjusted to suit the desired simulation. 


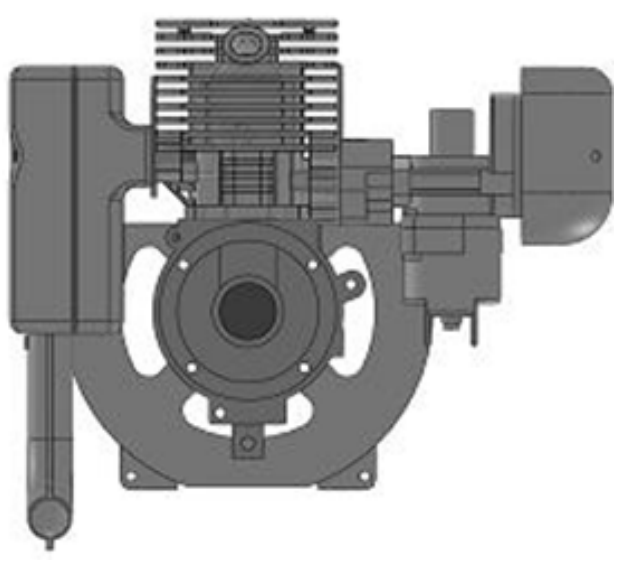

Fig. 2. Redesign of conventional engine type BG-328
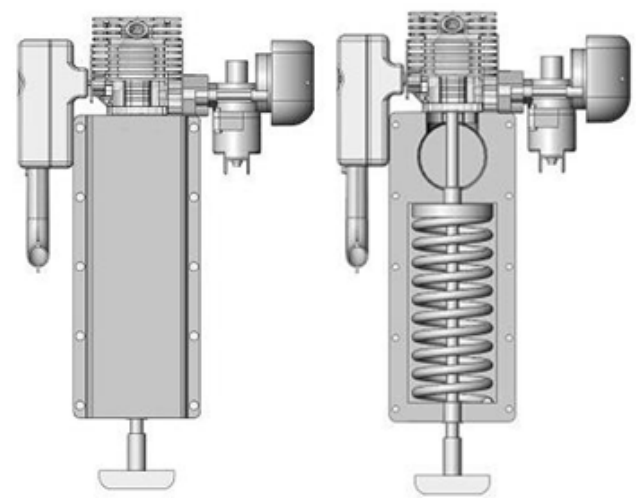

Fig. 3. Design of linear engine with spring mechanism with/without top casing

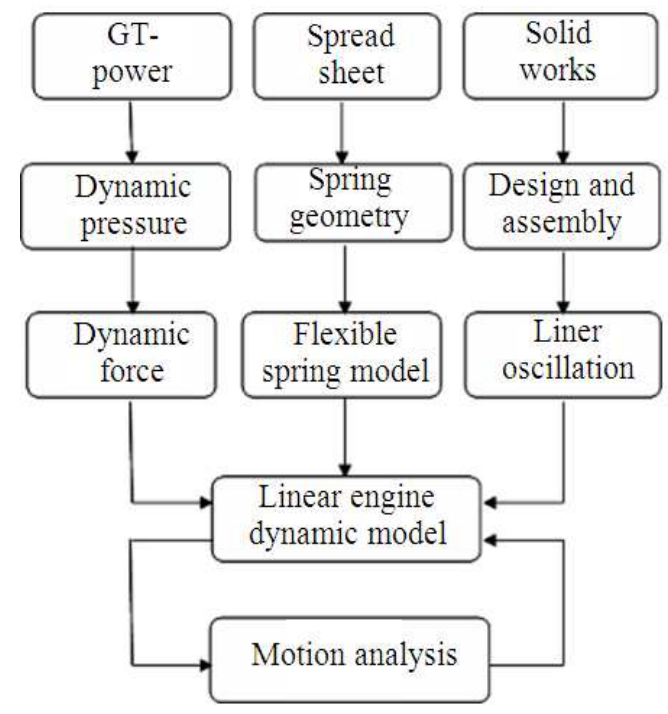

Fig. 4. Flow chart of motion analysis technique
Once the linear engine dynamics model can function properly, then an analysis of the motion can be conducted.

The modelling of the rotational engine is quite simple. Pressure data generated from the combustion processes are the same as the data used for the linear engines. It requires changing the linear motion to rotation by removing the linear motor and replacing it with a rotary motor. The dynamic model in this rotation is only used to study the basic movements, so the friction element of the piston is not studied in this research.

There are three objectives in this research, which are the basic considerations, the effect of friction and the effect of the spring design. The basic consideration is only needed due to the limitations of Cosmos motion at 1000 frames per second, as it is not good enough to simulate high-speed engines. A basic consideration is to understand the basic movements of the piston, especially to study the effect of friction on the piston's dynamics. Secondly, the dynamics of the piston at high-speed are studied. The effect of friction is also studied. Engines that run at $60 \mathrm{rpm}$ or $1 \mathrm{~Hz}$ is need learning purposes in the case of the basic consideration.

\section{RESULTS}

\subsection{Basic Considerations}

In basic considerations, different characteristics of conventional and linear engine motion, such as piston displacement, velocity and acceleration, are considered. The motion study runs in multi-cycles mode. The differences between both engines are shown in a single cycle. The speed of the engines have been set to slow speed.

Figure 5-6 presents the comparison between the trends of speed. Both engines have been simulated at 5 cycles with 1000 frames per cycle. However, on all cycles, each engine has a similar trend, although both engines have different characteristics. The conventional engine has faster and higher oscillations. On the other hand, is the oscillations are lower and wider than a linear engine. Somehow, both engines have the same elapsed time for every cycle.

Figure 7 shows the acceleration of both linear and conventional engines. The difference in characteristics between both engines is very clear. The acceleration of a conventional engine is 'fatter' than the linear one. The time period at the TDC is longer and then bends dramatically to the BDC. On the other hand, the BDC is slim. The characteristics of linear engines are different compared to conventional engines. The oscillation acceleration is consistent at the TDC and BDC. 


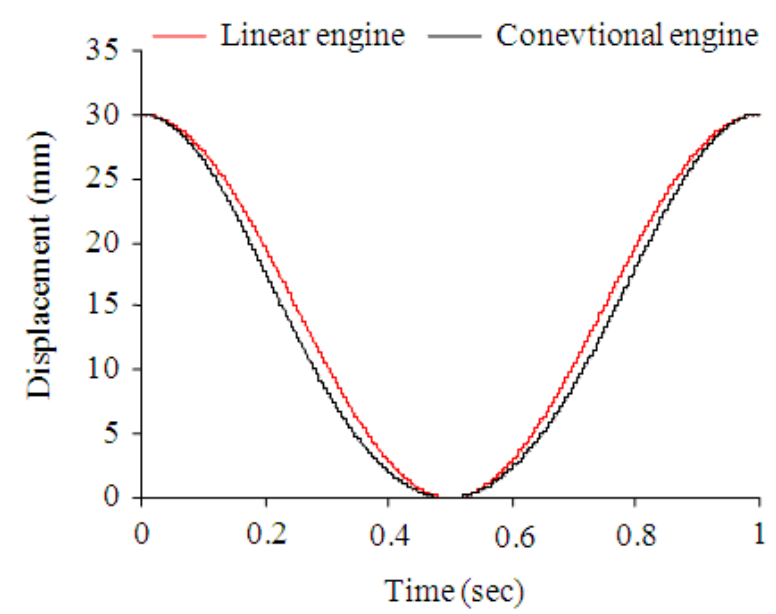

Fig. 5. Displacements of linear and conventional engines

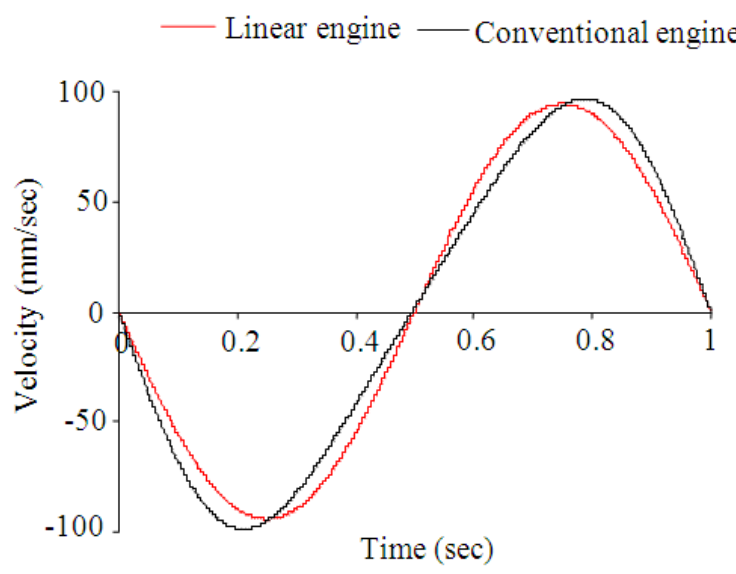

Fig. 6. Velocity of linear and conventional engines

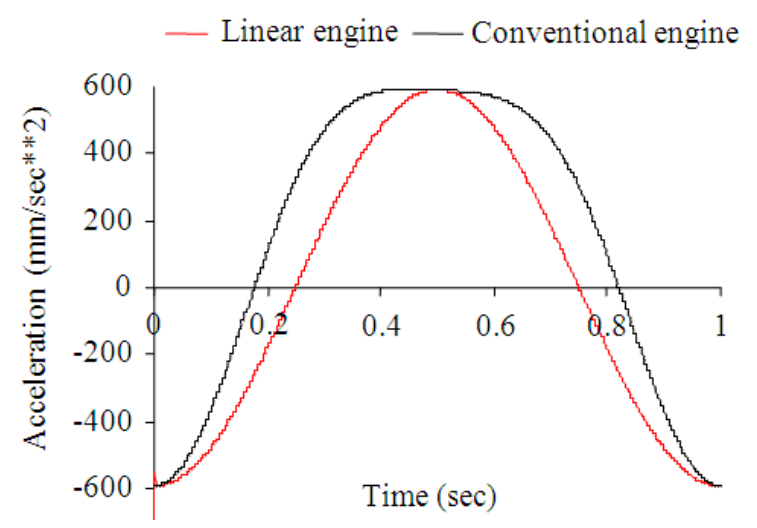

Fig. 7. Acceleration of linear and conventional engines

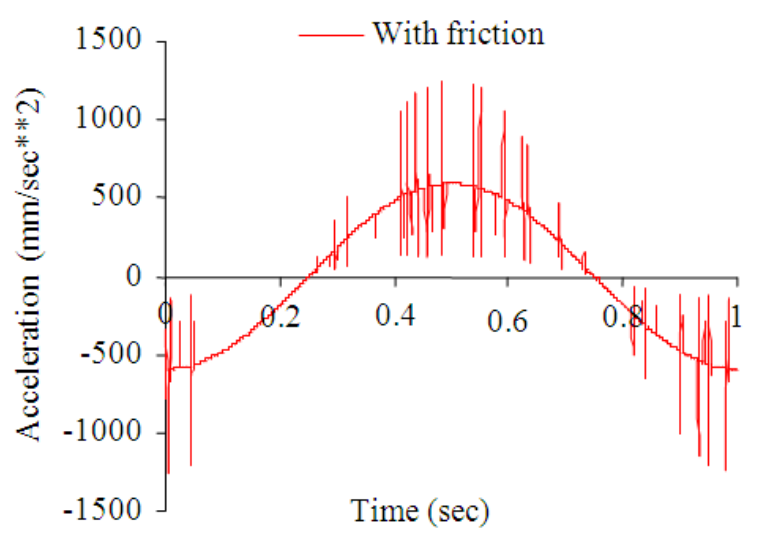

Fig. 8. Acceleration of linear engine with friction trend

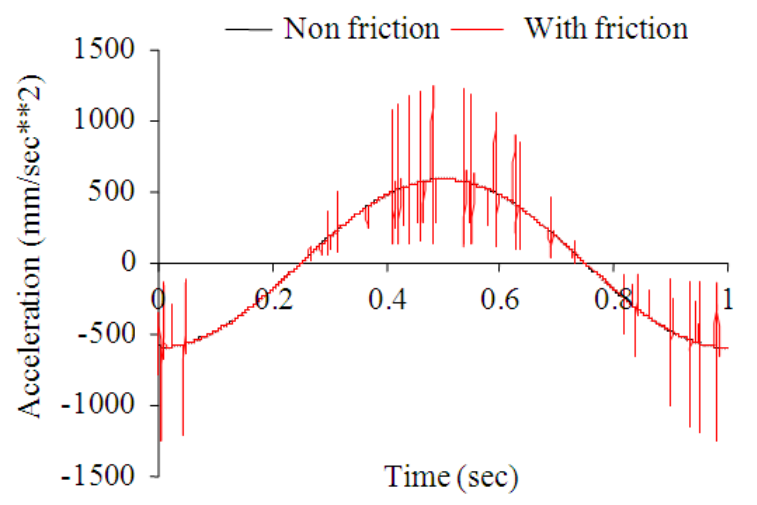

Fig. 9. Acceleration trend with and without friction

\subsection{Effect of Friction}

Friction has been studied and does not seem to affect trends in displacement and velocity. Friction strongly influences the acceleration, as shown in Figure 8 the effect is very strong at the TDC and BDC. The fluctuation, frame by frame, in the frictions is high at the TDC and BDC. If compared to nonfriction, it is very clear that the difference is a small part of the total. This figure has been observed at low speed and the recording is at 1000 frames per second. Because the recordings of data are good, then the result is very smooth and the trend graphs as well. Fluctuations of the frictions between piston and cylinder liner are also good choice of study to analyse.

Figure 9 presents a comparison of the acceleration trend between non-friction and friction, the bold black line is non-friction while the red line shows the friction trend. The differences between both trends are at fluctuation zones caused by friction forces. 


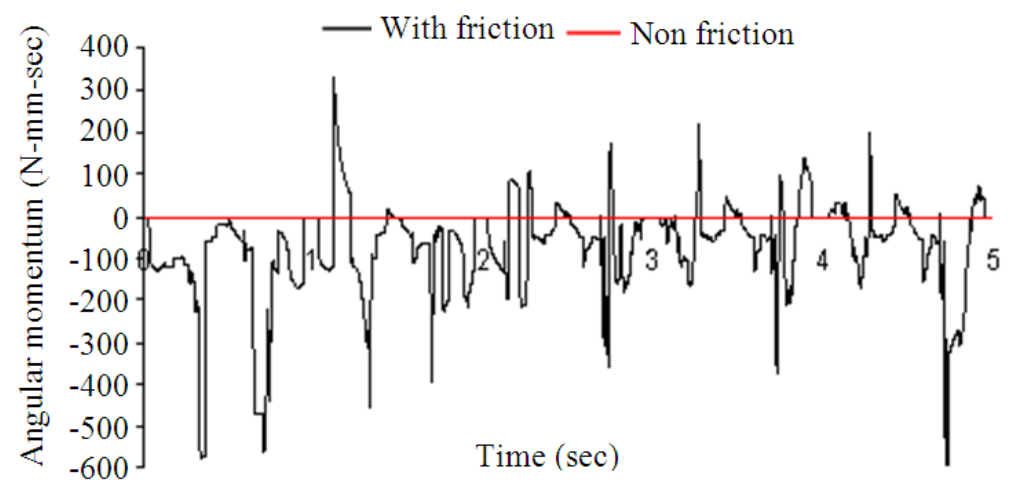

Fig. 10. Angular momentum with and without friction at $\mathrm{Z}$ ordinate

However, close to the TDC, large fluctuations are observed and the BDC also has the same trend. Figure 10 illustrates the angular momentum both with and without friction on the z-axis. There is no angular momentum when the friction force is not enforced. The amount of angular momentum is always shown on the $\mathrm{z}$-ordinate as long 5 times oscillations. A large angular momentum occurs when friction is applied. The angular momentum is fluctuating and the trend below the z-ordinate is possibly influenced by the force of gravity.

Figure 11 shows an image of real motions studies frames. In this study, the movements of the piston, cylinder head and other components at the top have been hidden. The images show the start of the first oscillation and every 1000 frames are selected and collected until the finish. The images also introduce rotary motion of the piston. The piston is rotated by about 90 degrees, which can be seen from the piston pin-hole which starts at the front in frame number 1 (F 1) and then moves every 1000 frames until finally it is displaced by about 90 degrees in frame number 5000 (F 5000).

\subsection{Effect of Spring Design}

Accordingly, the geometry of the spring design has been optimised using multilevel optimisation techniques. In fact, the performances of the gas dynamic do not always present the same trends, which can influence the spring system of linear engines. For that reason, the displacement, velocity and acceleration also need to be studied.

Figure 12 shows a predicted and designed displacement of a linear engine at a frequency 16.67 $\mathrm{Hz}$. The equality of frequency is shown at $1000 \mathrm{rpm}$, or $1 \mathrm{~m} \mathrm{sec}^{-1}$ in this engine. However, the oscillation of the predicted trend is about $29.99 \mathrm{~mm}$ at the TDC and only $26.95 \mathrm{~mm}$ for the design oscillation.

Figure 13 shows the displacements of the predicted and designed linear engine at a frequency of $66.67 \mathrm{~Hz}$. The trend is similar to that of the frequency of $16.67 \mathrm{~Hz}$ and is only different in terms of the values. The displacement of the predicted value is $29.7 \mathrm{~mm}$ and $27.4 \mathrm{~mm}$ for the designed value. The design displacement result is smaller than the prediction. This occurs because the combustion pressure is not high enough to compress the spring until maximum elevations at speeds of both $16.67 \mathrm{~Hz}$ and $66.67 \mathrm{~Hz}$.

Figures 14 and 15 show the velocity of the predicted and designed engine results at frequencies of 16.67 and $66.67 \mathrm{~Hz}$ respectively. Both figures have the same trend, the designed trend is smaller than predicted. Unlike the acceleration figure, the velocity trend was not influenced by friction. The predicted maximum velocity at a frequency of $16.67 \mathrm{~Hz}$ is $1536.24 \mathrm{~mm}$ $\mathrm{sec}^{-1}$ and is $1404.22 \mathrm{~mm} \mathrm{sec}^{-1}$ for the designed result.

The difference in maximum piston velocity for these two types of engine is $132.02 \mathrm{~mm} \mathrm{sec}^{-1}$. The velocity at the middle, TDC and BDC are zero. Negative velocity is mean on the bottom quadrant. Negative and positive values are dependent on the placement of the coordinates. However, the velocity is the same value with at the top site. The maximum velocities at a frequency of $66.67 \mathrm{~Hz}$, for both the predicted and designed engines, are $6263.05 \mathrm{~mm} \mathrm{sec}^{-1}$ and $5765.6 \mathrm{~mm} \mathrm{sec}^{-1}$, respectively. The difference in the maximum velocity of the predicted and designed engines is about $497.45 \mathrm{~mm} \mathrm{sec}^{-1}$. By increasing the frequency of linear engines, the velocity of the piston also increases. The difference in the maximum velocity of both engines also increases. 


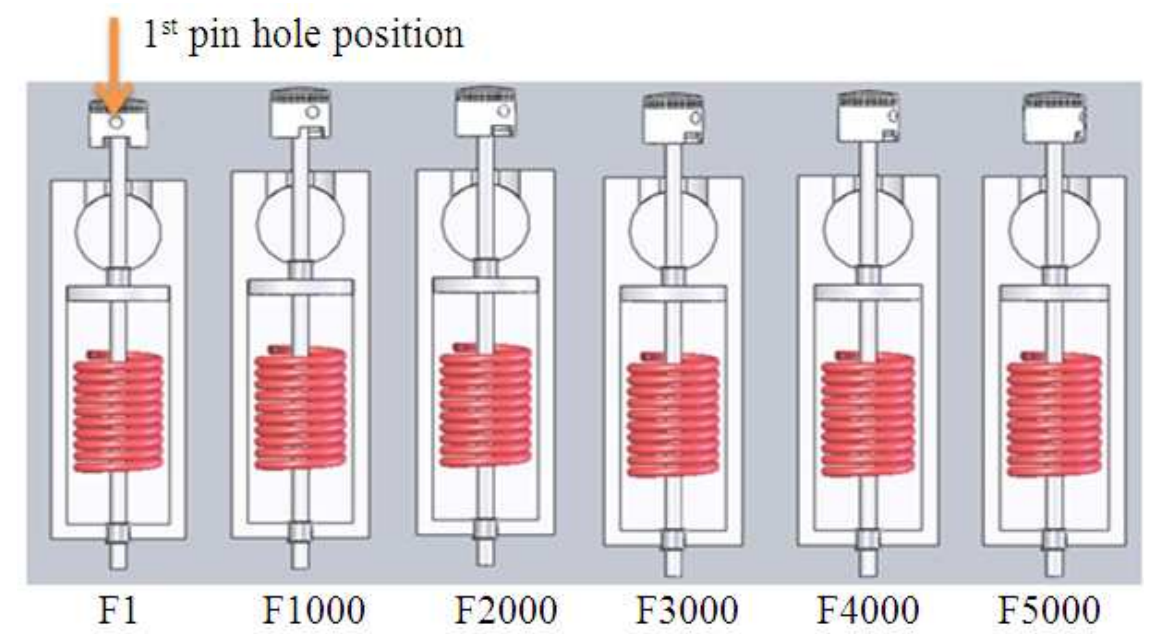

Fig. 11. Photograph of linear engine at certain frames

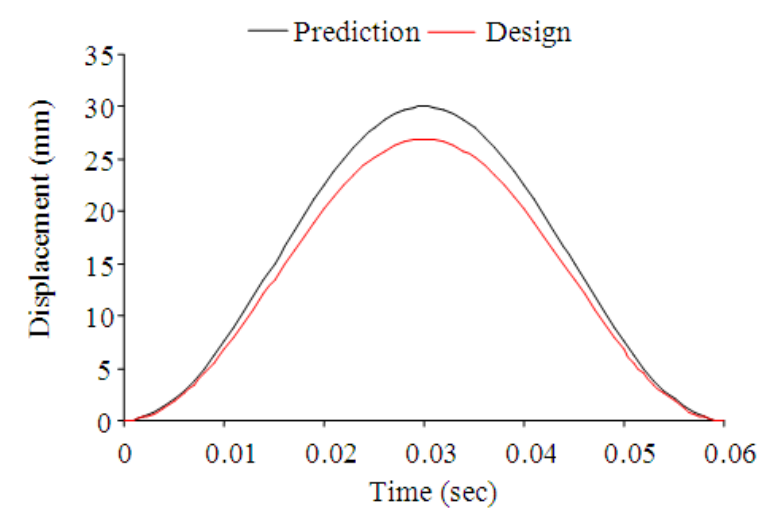

Fig. 12. Displacement trend of predicted and designed at 16.67 HZ

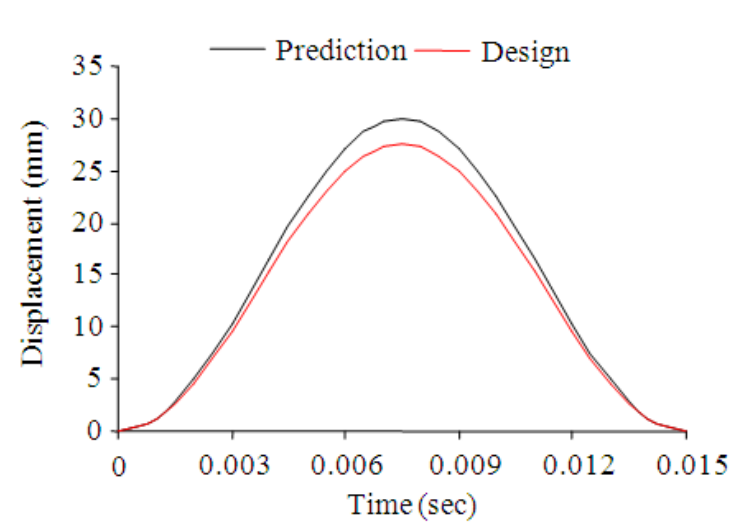

Fig. 13. Displacement trend of predicted and designed at 66.67 HZ

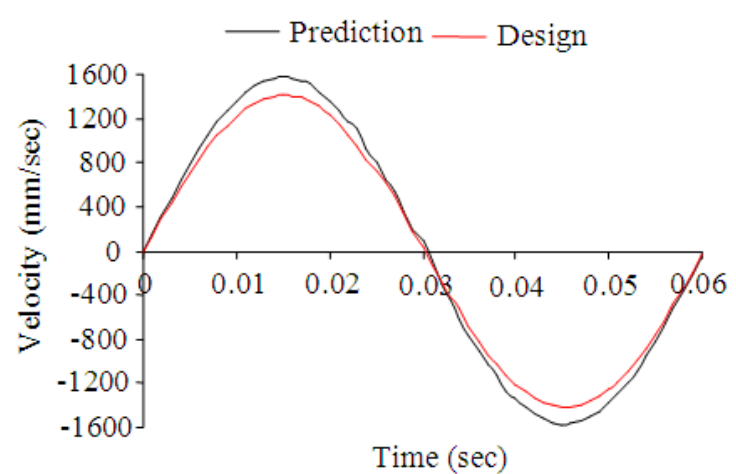

Fig. 14. Velocity of predicted and designed at frequency 16.67 HZ

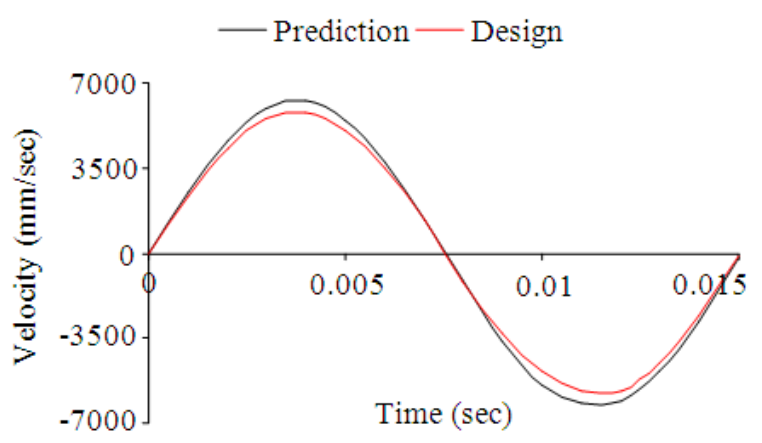

Fig. 15. Velocity of predicted and designed at frequency $66.67 \mathrm{HZ}$

Different piston acceleration trends between the predicted and designed models are difficult to study. 
Figure 16 shows the acceleration of engines at a frequency of $16.67 \mathrm{~Hz}$. It can be seen that the acceleration trend at the BDC and TDC fluctuates and is unsystematic. Figure 17 presents the acceleration trend at a frequency of $66.67 \mathrm{~Hz}$. Although the figure shows unsystematic fluctuation, it can be seen that the acceleration of the predicted engines is higher that in the designed engines, especially at the BDC. Compared to the acceleration produced at $16.67 \mathrm{~Hz}$, the trend in the acceleration at a frequency of $66.67 \mathrm{~Hz}$ shows the characteristics more clearly.

\section{DISCUSSION}

Based on basic consideration studies, the differences between conventional and linear engine characteristics are very clear in all motions such as displacement, velocity and acceleration.

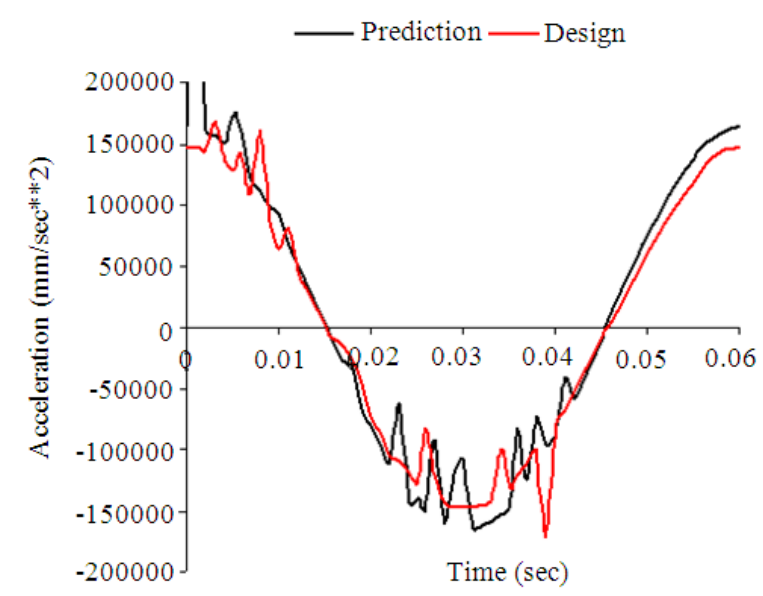

Fig. 16. Acceleration trend of predicted and designed at frequency 16.67

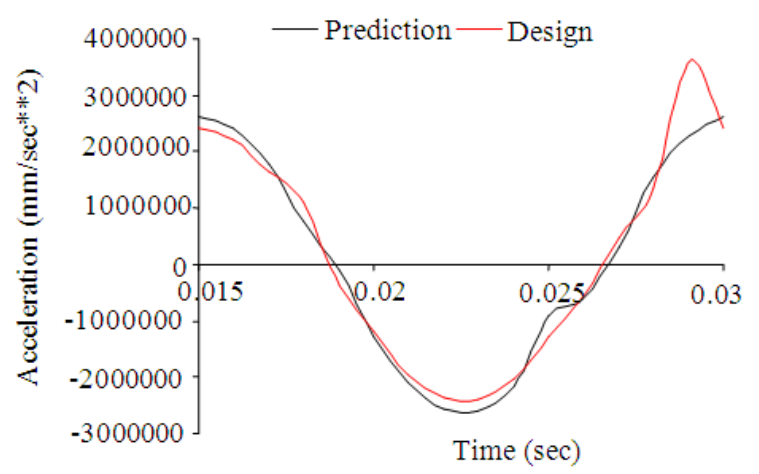

Fig. 17. Acceleration trend of predicted and designed at frequency $66.67 \mathrm{HZ}$
Most of researchers present similar results in that conventional and linear engines have different characteristics (Mikalsen and Roskilly, 2009; Fredriksson and Denbratt, 2004; Qingfeng et al., 2008). However the displacement trend is similar in both engines. The results of this study are closer to the results obtained by Fredriksson and Denbratt (2004) and Qingfeng et al. (2008). Although both engines show similar trends in piston velocity, the characteristics of the top piston velocity of linear engines are not dramatically different to the characteristics of the conventional engine. It might be that, in this comparison, both conventional and linear engines have the same characteristics for a single cylinder. Other researchers, however, have studied dual piston engines. In the case of conventional engines, it was found that the piston velocity trend has the same trend and the same characteristics as this research.

The piston acceleration of both engines also have similar trends, but some researchers have found that both engines have different characteristics (Mikalsen and Roskilly, 2008b; Fredriksson and Denbratt, 2004; Qingfeng et al., 2008). The high acceleration at the TDC and BDC is similar in both conventional and linear engines. However, for linear engines the piston acceleration at the TDC is slimmer but a little bit fatter at the BDC compared to that in conventional engines. It may be that conventional engines are influenced by the combustion process, spark timing (starting at $20^{\circ}$ BTDC) and the burning of fuels on elapse time with turbulence flame propagation. On the other hand, the return cycle of linear engines is compressed by springs which have a strong stiffness (depending on the design of the spring geometry); as a result, there is consistent piston acceleration at the TDC and BDC.

Friction very strongly affects the characteristics of linear engines with spring systems. Friction does not influence the displacement and velocity trend of the piston. However, acceleration characteristics, especially at the TDC and BDC, are strongly impacted on. Figure 8 and 9 clearly show the influence of friction on the acceleration characteristics. Figure 16 and 17 also introduce unsystematic trend characteristics caused by friction. Both characteristics are unclear since the engine runs at high speeds and the capacity of the software only reaches 1000 frames per second. It was not sufficient to simulate high frequency engine movement because there were much unrecorded data.

Friction also influences the piston movement. From a visual linear motion study, it is clear that a piston moves as shown in Figure 11. The rotary motion is strongly correlated with angular momentum. Figure $\mathbf{1 0}$ clearly 
shows that the angular momentum is very strong influenced by friction. However, the angular momentum rotates the piston by 90 degrees at 5000 frames. Accordingly, below the piston pinhole, there is a window of the inlet scavenging port. If the piston rotates 90 degrees then there no mixture will be supplied to the combustion chamber, which results in the engine misfiring and not run. This appears to be evidence that the designed linear engine may not work properly and that the spring system needs to be modified, especially the connection with the piston.

The design of the spring geometry is strongly influenced by the motion of a linear engine. A smaller piston displacement would influence both the compression ratio and scavenging. In this study, displacements on a certain frequency could not work properly. Frequencies of $16.67 \mathrm{~Hz}$ and $66.67 \mathrm{~Hz}$ resulted in the displacements being reduced to $26.95 \mathrm{~mm}$ and $27.4 \mathrm{~mm}$, respectively. Such displacements could affect the scavenging of the mixture and also decrease the pressure ratio. If a displacement decreases then the scavenging port window is also smaller and that influences the combustion process. If there is not enough fuel to burn then a smaller combustion pressure is produced; as a result there is smaller thrust force to push the piston. It is possible that a misfire will occur for a small displacement. Decreasing the pressure ratio also influences the combustion process. Therefore, decreasing the displacement very strongly influences the overall linear engine performance.

\section{CONCLUSION}

The motion analysis of a single cylinder in a highspeed spark ignition linear engine with a spring system as a return cycle has been investigated. 3-D conventional and linear engine models have been used to simulate piston motion, while GT-Power has been used to simulate the combustion pressure as input for the thrust forces. The geometry of the spring has been optimised with multilevel optimi sation using a spreadsheet. Solid Works has been used to design and assemble the model, while Cosmos is utilised to simulate motion analysis. According to the basic considerations, it showed a clear difference in motion between conventional and linear engines. Acceleration characteristics are very different. Conventional engine characteristics are inconsistent since there is a longer period at the TDC and then dramatically banded down to the BDC. On the other hand, the acceleration characteristic of a linear engine is consistent from the TDC to the BDC.
The friction force has a strong influence on the piston acceleration, especially in the TDC and BDC zones due to the extremely fluctuating trends. Moreover, the piston has a rotary motion which would influence the scavenging process. This is alarming for a two-stroke engine with a conventional scavenging piston control system. The pure free-piston could affect the combustion process of a linear engine. In this case, the spring system needs modification.

The geometry of the spring design at certain frequencies influences the displacement and pressure ratios. A decreasing displacement would reduce the area of the scavenging port, resulting in an insufficient supply of mixture to the combustion chamber. Moreover, the pressure ratio also drops depending on the decrease in the piston displacement.

\section{ACKNOWLEDGMENT}

The present research was funded by Indonesian Government Non-Tax Revenue (PNBP) 2012 through Laboratory Research Grant, Institute of Research and Public Service, Institut Teknologi Sepuluh Nopember Surabaya Indonesia. Special thanks to Mr. Indra, the Design and Computation Laboratory, Institut Teknologi Sepuluh Nopember for assisted research preparation and Mr. Fadzli, the FEMCOMP Laboratory, Universiti Malaysia Pahang, Malaysia.

\section{REFERENCES}

Ahmad, K.A., N.A.N. Mohamed and S. Fonna, 2006. Simulation of free piston with different intake and exhaust port position. J. Kejuruteraan, 18: 97-106.

Bakar, R.A. and A.R. Ismail, 2008a. Computational visualization and simulation of diesel engines valve lift performance using CFD. Am. J. Applied Sci., 5: 532-539. DOI: 10.3844/ajassp.2008.532.539

Bakar, R.A. and A.R. Ismail, 2008b. Investigation of diesel engine performance based on simulation. Am. J. Applied Sci., 5: 610-617. DOI: 10.3844/ajassp.2008.610.617

Christopher, M.A., S. Petreanu, N.N. Clark, R.J. Atkinson and T.I. McDaniel et al., 1999. Numerical simulation of a two-stroke linear engine-alternator combination. SAE Technical Paper Series, West Virginia University.

Fathallah, A.Z.M. and R.A. Bakar, 2009. Prediction studies for the performance of a single cylinder high speed spark ignition linier engine with spring mechanism as return cycle. Am. J. Eng. Applied Sci., 2: 720-727. DOI: 10.3844/ajeassp.2009.713.720 
Ferguson, C.R. and A.T. Kirkpatrick, 2000. Internal Combustion Engines: Applied Thermosciences. 2nd Edn., Jon Wiley and Sons, ISBN-10: 0471356174, pp: 384.

Fredriksson, J. and I. Denbratt, 2004. Simulation of a two-stroke free piston engine. CPL.

Ismail, A.R. and R.A. Bakar, 2008. An investigation of valve lift effect on air flow and coefficient of discharge of four stroke engines based on experiment. Am. J. Applied Sci., 5: 963-971. DOI: 10.3844/ajassp.2008.963.971

Mikalsen, R. and A.P. Roskilly, 2008a. The design and simulation of a two-stroke free-piston compression ignition engine for electrical power generation. Sci. Direct, Applied Thermal Eng., 28: 589-600. DOI: 10.1016/j.applthermaleng.2007.04.009

Mikalsen, R. and A.P. Roskilly, 2008b. The design and simulation of a two-stroke free-piston compression ignition engine for electrical power generator. Applied Thermal Eng., 28: 589-600. DOI: 10.1016/j.applthermaleng.2007.04.009
Mikalsen, R. and A.P. Roskilly, 2009. Coupled dynamicmultidimensional modelling of free-piston engine combustion. Applied Thermal Eng., 86: 89-95. DOI: 10.1016/j.apenergy.2008.04.012

Nik, A.M.N., A.K. Ariffin and S. Fonna, 2006. Simulation of a two-stroke spark ignition free piston linear motion. J. Teknologi Universiti Teknologi Malaysia, 44: 27-40.

Qingfeng, L., J. Xiao and Z. Huang, 2008. Simulation of a two-stroke free-piston engine for electrical power generation. Energy Fuels, 22: 3443-3449. DOI: 10.1021/ef800217k.

Zulkifli, S.A. M.N. Karsiti and A.R.A. Aziz, 2008. Starting of a free-piston linear engine-generator by mechanical resonance and rectangular current commutation. Proceedings of the Vecicle and Propulsion Conference, Sept. 3-5, IEEE Xplore Press, Harbin, pp: 1-7. DOI: 10.1109/VPPC.2008.4677748 